\title{
Genetic Variability and Selection Criteria in Rice Mutant Lines as Revealed by Quantitative Traits
}

\author{
Yusuff Oladosu, ${ }^{1}$ M. Y. Rafii, ${ }^{1,2}$ Norhani Abdullah, ${ }^{1,3}$ Mohammad Abdul Malek, ${ }^{1,4}$ \\ H. A. Rahim, ${ }^{5}$ Ghazali Hussin, ${ }^{6}$ Mohammad Abdul Latif, ${ }^{2,7}$ and Isiaka Kareem ${ }^{1}$ \\ ${ }^{1}$ Institute of Tropical Agriculture, Universiti Putra Malaysia (UPM), Serdang, 43400 Selangor, Malaysia \\ ${ }^{2}$ Department of Crop Science, Faculty of Agriculture, Universiti Putra Malaysia (UPM), Serdang, 43400 Selangor, Malaysia \\ ${ }^{3}$ Department of Biochemistry, Faculty of Biotechnology and Biomolecular Science, Universiti Putra Malaysia (UPM), \\ Serdang, 43400 Selangor, Malaysia \\ ${ }^{4}$ Bangladesh Institute of Nuclear Agriculture, Mymensingh 2202, Bangladesh \\ ${ }^{5}$ Bioscience and Agrotechnology Division, Malaysian Nuclear Agency, Bangi, 43000 Selangor, Malaysia \\ ${ }^{6}$ Strategic Livestock Research Centre, Malaysian Agricultural Research and Development Institute (MARDI), \\ Serdang, 43400 Selangor, Malaysia \\ ${ }^{7}$ Bangladesh Rice Research Institute (BRRI), Gazipur, Bangladesh
}

Correspondence should be addressed to M. Y. Rafii; mrafii@upm.edu.my

Received 5 July 2014; Revised 8 September 2014; Accepted 8 September 2014; Published 5 November 2014

Academic Editor: Jean Louis Hilbert

Copyright (C) 2014 Yusuff Oladosu et al. This is an open access article distributed under the Creative Commons Attribution License, which permits unrestricted use, distribution, and reproduction in any medium, provided the original work is properly cited.

Genetic based knowledge of different vegetative and yield traits play a major role in varietal improvement of rice. Genetic variation gives room for recombinants which are essential for the development of a new variety in any crop. Based on this background, this work was carried out to evaluate genetic diversity of derived mutant lines and establish relationships between their yield and yield components using multivariate analysis. To achieve this objective, two field trials were carried out on 45 mutant rice genotypes to evaluate their growth and yield traits. Data were taken on vegetative traits and yield and its components, while genotypic and phenotypic coefficients, variance components, expected genetic advance, and heritability were calculated. All the genotypes showed variations for vegetative traits and yield and its components. Also, there was positive relationship between the quantitative traits and the final yield with the exception of number of tillers. Finally, the evaluated genotypes were grouped into five major clusters based on the assessed traits with the aid of UPGMA dendrogram. So hybridization of group I with group V or group VI could be used to attain higher heterosis or vigour among the genotypes. Also, this evaluation could be useful in developing reliable selection indices for important agronomic traits in rice.

\section{Introduction}

Rice (Oryza sativa) is an important staple food in the world. Despite its position among the highly rated cereals, it feeds more than half of the world's population. The geometric growth rate of the global population has called for yield improvement of this very important cereal. On this, several methods have been tried by scientists to combat this perennial problem. Some researchers have tried nutritional method, physiological method, and breeding as well as control of pests and diseases. Among these methods, it is established that breeding for high yield traits is the most sustainable because the traits are heritable. To achieve this breeding objective, changes at cellular level are employed to get traits that could improve yield. These changes are referred to as mutations and may occur either in the genes or at chromosomal level to bring the desired improvement. At present, improvement of major food crops in the world rests majorly on mutation. This comes either naturally or through irradiation. So crops with restriction in genetic variation require mutagenesis or induced mutation to create desirable and heritable variations in them [1]. Following this, the use of induced mutations has been extensively used for genetic enhancement of different crops $[2,3]$. Ionizing radiation of 
high frequencies and chemical mutagens are being employed to achieve genetic enhancement among various mutagenic agents available to induce favourable mutations. The mechanism of operation of ionizing radiation hinges on the level of the energy absorbed by the biological system of the plants or plant parts. The primary system which is the most important target in energy absorption is the chromosome [4]. Through this, there will be chromosomal changes which will manifest themselves in the subsequent progenies. The use of seed irradiation to achieve chromosomal changes has been found to increase frequencies of mutation and promote gene recombination which in turn promotes recombination and leads to mutation spectrum widening [5]. Based on radiation mutation, plant breeding has officially released over 2700 new crop cultivars in approximately 170 species [6].

Development of high-yielding cultivars requires a thorough knowledge of genetic variation in yield and its component among the existing cultivars. This is sine qua non to high-yielding cultivar development. Any variation observed in organisms is the result of combination of estimate of both genetic and environmental causes. Out of these two, only genetic cause is heritable. To get complete expectation of plant response to selection, only heritability estimate is not enough. So it should be combined with other estimates like genotypic and phenotypic coefficients of variation, genetic advance, and change in mean value between generations [7]. Extensive uses of gamma and $\mathrm{x}$-rays in inducing mutations in crop plants have been well established. Therefore, successful adoption of this technology requires knowing the optimum dose for irradiating plant materials. At the same time, sound management of variations resulting from induction has to be embarked upon [8].

MR219 rice variety was developed by the Malaysian Agricultural Research and Development Institute (MARDI) and officially released in January 2001. It was the first variety to be developed by means of a direct seeding planting system. The emphasis was on the panicle characteristics. These are mainly the grain size and number of grains per panicle. As a result, a single grain of MR219 variety can weigh as much as $28-30 \mathrm{mg}$, and the number of grains can be as high as 200 . This is higher than the previously released varieties. Other characteristics of this variety include short life cycle (105-111 days), fairly long but strong culms, and resistance to blast and bacterial leaf blight. Therefore, it could be marketed as a longgrain variety. In addition, cooked form of MR219 has soft texture (amylase content of $21.4 \%$ ). This is the preference of most local consumers. It is the most cultivated variety grown in Malaysia, covering almost $90 \%$ of cultivated area [9].

Breeders are interested in evaluating genetic diversity based on morphological characteristics because they are inexpensive, rapid, and simple to score. The study of these characteristics does not require sophisticated equipment. Moreover, they can be inherited without specific biochemical or molecular techniques. Also, this evaluation could be useful in developing reliable selection indices for important agronomic traits in rice. Therefore, the present study was conducted to evaluate genetic diversity of derived mutant lines of MR219 and establish relationship between yield and yield components in the mutant lines using multivariate analysis.

\section{Materials and Methods}

2.1. Experimental Site and Plant Husbandry. Because MR219 is the most cultivated rice variety in Malaysia, covering almost $90 \%$ of the cultivated areas [9], efforts are constantly being made to increase its yield potentials. Therefore, its seeds were irradiated with an ion beam for radiosensitivity determination. A total of 100 seeds were subjected to 0 , $10,20,40,60,80,100,120,160$, and 200 Gray (Gy) to determine the optimum doses for the production of high mutant frequency and spectrum. The optimum dose was found to be $60 \mathrm{~Gy}$. The $\mathrm{M}_{1}$ seedlings were transplanted into the field with $25 \mathrm{~cm} \times 25 \mathrm{~cm}$ planting distance. Ten thousand $M_{1}$ seedlings were planted to produce $M_{2}$ seeds and a total of 5,250 plants were selected from which 2 panicles per hill were randomly harvested from each hill. About $5 \%$ of $M_{2}$ populations were selected for further screening in $M_{3}$. After several series of selection and fixation, 31 potential lines with the required adaptive traits were recovered at $\mathrm{M}_{4}$ generation during the 2009-2012 seasons $\left(\mathrm{M}_{0}-\mathrm{M}_{4}\right)$. In total, forty-five rice genotypes, which formed three populations (Malaysia, Vietnam, and Bangladesh), were analysed. Of these 45 genotypes, 31 were mutant lines derived from MR219, 4 were other commercial varieties from Malaysia, 8 were commercial mutant varieties from Bangladesh, and 2 were mutant varieties from Vietnam (Table 1). The field evaluation was carried out repeatedly in two locations on M4 generation. The first location was field 10 of the Universiti Putra Malaysia (UPM). It was $31 \mathrm{~m}$ above the sea level and is located between latitude $3^{\circ} 02^{\prime} \mathrm{N}$ and longitude $101^{\circ} 42^{\prime} \mathrm{E}$. The second location was the farmers' field in Melor, Kelantan, Malaysia. It was located between latitude $5.9833^{\circ} \mathrm{N}$ and longitude $102.3^{\circ} \mathrm{E}$. The climate of the two locations was a hot humid tropic. The areas fell under the rain forest. The periods of cultivation were December 2012 to April 2013 and February to June 2013. $30 \mathrm{~g}$ of each rice accession was placed in plastic petri dishes and oven-dried at $50^{\circ} \mathrm{C}$ for 24 hours to break seed dormancy. The seeds were then pregerminated and finally transferred into a nursery for proper establishment. 21-day-old seedlings were then transplanted into a field of size $22 \mathrm{~m}$ by $18 \mathrm{~m}$. The plant spacing was $25 \mathrm{~cm}$ by $30 \mathrm{~cm}$ with density of two seedlings per stand. This experiment was laid out in randomized complete block (RCB) with three replications. The fields were irrigated throughout the experiment with average of $10 \mathrm{~cm}$ water above the soil level. Regular hand weeding was embarked upon to free the plant of interspecific competition. Fertilizer was applied in splits using $57 \mathrm{~kg} / \mathrm{ha}$ triple super phosphate, $42 \mathrm{~kg} / \mathrm{ha}$ muriate of potash, and $80 \mathrm{~kg} / \mathrm{ha}$ urea at 15, 35, 55, and 75 days after planting. Insecticides (Malathion and Hopper Gun) were applied for controlling insect pests as required at recommended rates.

2.2. Data Collection. From each variety, five plants were randomly sampled from each block for data collection. Data collection was on plant height, flag leaf length to width ratio, number of tillers per hill, days to flowering, days to maturity, number of panicles per hill, panicle length, total number of 
TABLE 1: List of rice genotypes studied.

\begin{tabular}{|c|c|c|c|}
\hline $\begin{array}{l}\text { Genotype } \\
\text { code }\end{array}$ & $\begin{array}{c}\text { Name of } \\
\text { accession }\end{array}$ & State & Mutagenesis source \\
\hline GN1 & ML-1 & Mutant line & Ion beam \\
\hline GN2 & ML-2 & Mutant line & Ion beam \\
\hline GN3 & ML-3 & Mutant line & Ion beam \\
\hline GN4 & ML-4 & Mutant line & Ion beam \\
\hline GN5 & ML-5 & Mutant line & Ion beam \\
\hline GN6 & ML-6 & Mutant line & Ion beam \\
\hline GN7 & ML-7 & Mutant line & Ion beam \\
\hline GN8 & ML-8 & Mutant line & Ion beam \\
\hline GN9 & ML-9 & Mutant line & Ion beam \\
\hline GN10 & ML-10 & Mutant line & Ion beam \\
\hline GN11 & ML-11 & Mutant line & Ion beam \\
\hline GN12 & ML-12 & Mutant line & Ion beam \\
\hline GN13 & ML-13 & Mutant line & Ion beam \\
\hline GN14 & ML-14 & Mutant line & Ion beam \\
\hline GN15 & ML-15 & Mutant line & Ion beam \\
\hline GN16 & ML-16 & Mutant line & Ion beam \\
\hline GN17 & ML-17 & Mutant line & Ion beam \\
\hline GN18 & ML-18 & Mutant line & Ion beam \\
\hline GN19 & ML-19 & Mutant line & Ion beam \\
\hline GN20 & ML-20 & Mutant line & Ion beam \\
\hline GN21 & ML-21 & Mutant line & Ion beam \\
\hline GN22 & ML-22 & Mutant line & Ion beam \\
\hline GN23 & ML-23 & Mutant line & Ion beam \\
\hline GN24 & ML-24 & Mutant line & Ion beam \\
\hline GN25 & ML-25 & Mutant line & Ion beam \\
\hline GN26 & ML-26 & Mutant line & Ion beam \\
\hline GN27 & ML-27 & Mutant line & Ion beam \\
\hline GN28 & ML-28 & Mutant line & Ion beam \\
\hline GN29 & ML-29 & Mutant line & Ion beam \\
\hline GN30 & ML-30 & Mutant line & Ion beam \\
\hline GN31 & ML-31 & Mutant line & Ion beam \\
\hline GN32 & MR 219 & Released variety & $\begin{array}{l}\text { Conventional } \\
\text { method }\end{array}$ \\
\hline GN33 & MR 220 & Released variety & $\begin{array}{c}\text { Conventional } \\
\text { method }\end{array}$ \\
\hline GN34 & MR 253 & Released variety & $\begin{array}{c}\text { Conventional } \\
\text { method }\end{array}$ \\
\hline GN35 & MR 264 & Released variety & $\begin{array}{l}\text { Conventional } \\
\text { method }\end{array}$ \\
\hline GN36 & Binadhan-4 & Released variety & Gamma ray \\
\hline GN37 & Binadhan-5 & Released variety & Gamma ray \\
\hline GN38 & Binadhan-6 & Released variety & Gamma ray \\
\hline GN39 & Binadhan-7 & Released variety & Gamma ray \\
\hline GN40 & Binadhan-10 & Released variety & Gamma ray \\
\hline GN41 & Binadhan-8 & Released variety & Gamma ray \\
\hline GN42 & IRATOM-38 & Released variety & Gamma ray \\
\hline GN43 & Binasail & Released variety & Gamma ray \\
\hline GN44 & VN-124 & Released variety & Gamma ray \\
\hline GN45 & $\mathrm{VN}-121$ & Released variety & Gamma ray \\
\hline
\end{tabular}

NB: ML: mutant line. grain per panicle, 100 grain weight, total grain weight per hill, seed length, seed length to width ratio and yield in $t / h a$ (Table 2).

2.3. Variance Components. Variance components were estimated to determine genetic variation among genotypes and to assess genetic and environmental effects on different traits. The variance components were calculated as follows.

$$
\begin{aligned}
& \text { 2.4. Genotypic Variance }\left(\sigma_{g}^{2}\right) \text {. Consider } \\
& \qquad \sigma_{g}^{2}=\frac{(\mathrm{MSG}-\mathrm{MSE})}{r},
\end{aligned}
$$

where MSG is mean square of genotypes, MSE is mean square of the error, and $r$ is number of replications.

$$
\begin{aligned}
& \text { 2.5. Phenotypic Variance }\left(\sigma_{p}^{2}\right) \text {. Consider } \\
& \qquad \sigma_{p}^{2}=\sigma_{g}^{2}+\sigma_{e}^{2},
\end{aligned}
$$

where $\sigma_{g}^{2}$ is genotypic variance and $\sigma_{e}^{2}$ is the mean squares of error.

$$
\begin{aligned}
& \text { 2.6. Error Variance }\left(\sigma_{e}^{2}\right) \text {. Consider } \\
& \sigma_{e}^{2}=\mathrm{MSE},
\end{aligned}
$$

where MSE is the mean square of error.

2.7. Phenotypic and Genotypic Coefficient of Variation (PCV and $G C V$ ). The estimates of phenotypic and genotypic coefficient of variation were calculated according to Singh and Choudhary [10] as follows:

$$
\begin{aligned}
& \mathrm{PCV}=\frac{\sqrt{\sigma_{P}^{2}}}{\bar{X}} \times 100, \\
& \mathrm{GCV}=\frac{\sqrt{\sigma_{g}^{2}}}{\bar{X}} \times 100 .
\end{aligned}
$$

$\sigma_{P}^{2}$ is the phenotypic variance. $\sigma_{g}^{2}$ is the genotypic variance. $\bar{X}$ is the mean of the trait. GCV and PCV values were categorized as low $(0-10 \%)$, moderate $(10-20 \%)$, and high (20\% and above) following Sivasubramanian and Madhava Menon [11].

2.8. Heritability Estimate. This heritability $h_{B}^{2}$ (broad sense) is the ratio of genetic variance $\left(\sigma_{g}^{2}\right)$ to phenotypic variance $\left(\sigma_{p}^{2}\right)$ [12]. It is calculated as

$$
h_{B}^{2}=\frac{\sigma_{g}^{2}}{\sigma_{p}^{2}},
$$

where $\sigma_{g}^{2}$ is the genotypic variance and $\sigma_{p}^{2}$ is the phenotypic variance.

The heritability percentage was categorized as low $(0-$ $30 \%)$, moderate $(30-60 \%)$, and high $(\geq 60 \%)$ in accordance with Robinson et al. [13]. 
TABLE 2: List of quantitative traits.

\begin{tabular}{|c|c|c|}
\hline Growth trait/yield trait & Denotation & Method of evaluation \\
\hline Plant height & $\mathrm{PH}(\mathrm{cm})$ & The average height from the base to the tip of last leaf (flag leaf) \\
\hline Flag leaf length to width ratio & FLWR $(\mathrm{cm})$ & Divide the flag leaf length by width \\
\hline Number of tillers per hill & NT (number) & Count the number of tillers per hill \\
\hline Days to flowering & DF (days) & Count the number of days from seeding to flowering \\
\hline Days to maturity & $\mathrm{DM}$ (days) & Count the number of days from seeding to maturity \\
\hline Number of panicles per hill & $\mathrm{NP} / \mathrm{H}$ (number) & Count the number of panicles per hill \\
\hline Panicle length & $\mathrm{PL}(\mathrm{cm})$ & $\begin{array}{l}\text { Measure the length from the node below the lowest branch on the panicle to the } \\
\text { top of first superior spikelet }\end{array}$ \\
\hline Total number of grain per panicle & TNG/P (number) & Count the number of spikelets per panicle \\
\hline Hundred grain weight & $100 \mathrm{GW}(\mathrm{g})$ & Weigh any 100 filled grains \\
\hline Total grain weight per hill & TGW/H (g) & Weigh total grains produced per hill \\
\hline Seed length & $\mathrm{SL}(\mathrm{cm})$ & $\begin{array}{l}\text { Measure the length of the seeds using microscopic picture and Leica application } \\
\text { suit software }\end{array}$ \\
\hline Seed length to width ratio & SLWR $(\mathrm{cm})$ & Divide the seed length by width \\
\hline Yield in $\mathrm{t} / \mathrm{ha}$ & $\mathrm{Y} / \mathrm{ha}$ (ton) & Number of tillers per square meter $\times$ average total grains per tillers divided by 100 \\
\hline
\end{tabular}

2.9. Estimated and Expected Genetic Advance. Expected genetic advance (GA) (as percentage of the mean) was calculated using the method of Assefa et al. [14] and selection intensity $(K)$ was assumed to be $5 \%$. Genetic advance was categorized as low (0-10\%), moderate (10-20\%), and high (>20\%) by following [15].

$$
\begin{gathered}
\mathrm{GA}=K \times \sqrt{\sigma_{p}^{2}} \times h_{B}^{2}, \\
\mathrm{GA}(\%)=K \times \frac{\sqrt{\sigma_{P}^{2}}}{\bar{X}} \times h_{B}^{2} \times 100 .
\end{gathered}
$$

$K$ is a constant which represents the selection intensity. When $k$ is $5 \%$, the value is $2.06 . \sqrt{\sigma_{P}^{2}}$ is phenotypic standard deviation, $h_{B}^{2}$ is the heritability, and $\bar{X}$ is the mean of traits.

2.10. Cluster Analysis. In this study, cluster and principal component analysis (PCA) were used to assess the genetic diversity of quantitative traits [16]. Cluster analysis grouped individuals on the basis of their characteristics. So individuals having similar characteristics were mathematically clustered together using distance, similarity, and relatedness of varieties as the basis. On the basis of distance, clustering was done.

2.11. Data Analysis. All the morphological and yield data collected were subjected to analysis of variance (ANOVA) while significant means were separated with least significant difference (LSD) using SAS 9.1 software. Also mean, range, standard deviation, and coefficient of variation $(\mathrm{CV})$ were recorded for each trait measured. The relationships among the traits were also determined using correlation analysis. Genetic variance data generated were analysed based on Euclidian distance method, Dice's and Jaccard's similarity coefficient. Genetic relationships among the rice genotypes were determined using UPGMA algorithm and SAHN methods. All these were achieved with NTSYS-pc 2.1 software.

\section{Results}

3.1. Genetic Variation for Vegetative Characters. From the pooled data of the two sites, there were significant differences among yield components. Five parameters related to plant vegetative growth were analysed for variation assessment (Table 3). The varietal impact on plant height was significant for all the genotypes $(P<0.01)$. The plant height varied from 147.67 to $71.74 \mathrm{~cm}$. The tallest plant $(147.67 \mathrm{~cm})$ was from Binasail, whereas the shortest plant $(71.74 \mathrm{~cm})$ was from IRATOM-38. The genotypes MR 219, MR 220, ML-16, ML11, ML-24, ML-7, ML-18, ML-19, ML-22, ML-25, ML-4, ML27, ML-31, ML-30, ML-5, and ML-29 were similar in height. Their height was an intermediate one. The values for flag leaf length to width ratio (FLWR) ranged from 72.89 to 22.32. The Binasail genotype had the highest value, whereas VN121 had the lowest value. In the case of number of tillers (NT) per hill, the values were between 26 and 14. The highest number of tillers (26) was from Binasail whereas the lowest number (14) was from ML-7 and ML-12. However, ML-3, ML16, ML-24, ML-17, ML-6, ML-9, ML-30, ML-15, and ML-28 were statistically equal to one another. The number of days to $50 \%$ flowering was between 53 and 77 days, as observed in IRATOM-38 and ML7, respectively. Days to maturity varied significantly $(P<0.01)$ among the genotypes and range was from 85 to 124 days. The earliest maturing ( 85 days) genotype was IRATOM-38 while genotype Binasail matured last (124 days). ML-2, ML-5, ML-17, ML-29, ML-31, ML-1, ML-2, ML-3, ML-16, ML-13, ML-18, ML-6, ML-21, ML-27, ML-20, MR 220, and ML-9 had similar average number of days to maturity.

3.2. Yield and Its Components. Eight parameters on rice yield were analysed for genetic variability (Table 3 ). The number of panicles per hill varied from 21 to 13 . The highest number 
TABLE 3: Morphological traits, yield and yield components of rice accession for the two location.

\begin{tabular}{|c|c|c|c|c|c|c|c|c|c|c|c|c|c|}
\hline Accession & $\begin{array}{l}\mathrm{PH}, \\
(\mathrm{cm})\end{array}$ & $\begin{array}{l}\text { FLR, } \\
(\mathrm{cm})\end{array}$ & NT (no.) & $\begin{array}{c}\text { DF, } \\
\text { (days) }\end{array}$ & $\begin{array}{c}\mathrm{DM}, \\
\text { (days) }\end{array}$ & $\begin{array}{c}\mathrm{NP} / \mathrm{H}, \\
\text { (no.) }\end{array}$ & $\begin{array}{c}\mathrm{PL}, \\
(\mathrm{cm})\end{array}$ & $\begin{array}{c}\text { TNG/P, } \\
\text { (no.) }\end{array}$ & $\begin{array}{c}100 \mathrm{GW} \\
(\mathrm{g})\end{array}$ & $\begin{array}{c}\text { TGW/H } \\
(\mathrm{g})\end{array}$ & $\begin{array}{c}\mathrm{SL}, \\
(\mathrm{mm})\end{array}$ & $\begin{array}{l}\text { SLWR } \\
(\mathrm{mm})\end{array}$ & $\begin{array}{l}\text { Y/ha, } \\
\text { (t/ha) }\end{array}$ \\
\hline ML-1 & 88.80 & 34.17 & 19.5 & 72.5 & 111.5 & 17.8 & 24.17 & 141.2 & 2.55 & 33.26 & 7.52 & 2.22 & 5.32 \\
\hline ML-2 & 86.13 & 39.27 & 15.8 & 72.0 & 111.0 & 15.7 & 22.83 & 145.7 & 2.31 & 26.60 & 7.18 & 2.13 & 4.26 \\
\hline ML-3 & 89.07 & 40.32 & 17.8 & 72.8 & 111.8 & 17.0 & 24.17 & 157.0 & 2.85 & 30.22 & 8.06 & 2.34 & 4.84 \\
\hline ML-4 & 84.27 & 47.37 & 14.5 & 71.8 & 106.7 & 14.0 & 23.17 & 204.7 & 2.67 & 42.21 & 7.65 & 2.29 & 6.72 \\
\hline ML-5 & 83.47 & 38.86 & 16.2 & 72.2 & 111.2 & 15.5 & 24.00 & 142.5 & 2.47 & 21.12 & 7.76 & 2.25 & 3.38 \\
\hline ML-6 & 91.27 & 41.09 & 17.3 & 73.7 & 112.7 & 16.2 & 24.33 & 152.3 & 2.41 & 40.48 & 7.95 & 2.32 & 6.48 \\
\hline ML-7 & 85.27 & 39.65 & 14.0 & 76.5 & 115.5 & 13.2 & 24.67 & 157.7 & 2.42 & 28.80 & 7.68 & 2.26 & 4.61 \\
\hline ML-8 & 82.73 & 40.44 & 18.5 & 75.3 & 114.3 & 16.2 & 24.67 & 156.3 & 2.52 & 32.27 & 7.63 & 2.27 & 5.16 \\
\hline ML-9 & 88.87 & 45.89 & 17.3 & 75.7 & 113.3 & 16.2 & 24.50 & 187.8 & 2.72 & 44.55 & 7.77 & 2.25 & 7.13 \\
\hline ML-10 & 90.40 & 48.26 & 15.8 & 73.3 & 110.3 & 16.2 & 23.83 & 206.8 & 2.81 & 40.79 & 7.60 & 2.30 & 6.53 \\
\hline ML-11 & 86.53 & 38.79 & 15.2 & 75.3 & 114.3 & 15.3 & 24.17 & 152.5 & 2.48 & 29.46 & 7.32 & 2.14 & 4.71 \\
\hline ML-12 & 87.07 & 33.98 & 14.0 & 75.8 & 114.8 & 12.8 & 23.50 & 130.2 & 2.51 & 17.91 & 7.29 & 2.15 & 2.87 \\
\hline ML-13 & 88.67 & 35.54 & 18.3 & 73.3 & 112.3 & 16.5 & 23.83 & 160.0 & 2.63 & 39.65 & 7.62 & 2.19 & 6.34 \\
\hline ML-14 & 89.27 & 45.84 & 16.7 & 70.0 & 109.0 & 15.0 & 22.83 & 141.2 & 2.42 & 29.47 & 7.86 & 2.40 & 4.72 \\
\hline ML-15 & 88.00 & 42.22 & 17.2 & 71.8 & 110.8 & 16.5 & 24.33 & 157.3 & 2.51 & 26.81 & 7.45 & 2.20 & 4.29 \\
\hline ML-16 & 86.73 & 35.37 & 17.8 & 73.3 & 112.3 & 17.2 & 25.33 & 172.3 & 2.54 & 32.91 & 7.78 & 2.32 & 5.27 \\
\hline ML-17 & 84.87 & 43.95 & 17.3 & 72.2 & 111.2 & 14.8 & 24.17 & 160.0 & 2.55 & 28.71 & 7.76 & 2.27 & 4.59 \\
\hline ML-18 & 85.27 & 36.73 & 15.2 & 73.5 & 112.5 & 14.5 & 25.00 & 163.2 & 2.55 & 31.68 & 7.88 & 2.36 & 5.07 \\
\hline ML-19 & 84.40 & 40.82 & 16.3 & 73.0 & 110.3 & 15.8 & 24.33 & 142.7 & 2.44 & 33.72 & 7.67 & 2.30 & 5.40 \\
\hline ML-20 & 87.73 & 39.97 & 19.7 & 73.5 & 113.2 & 19.7 & 24.67 & 146.5 & 2.62 & 27.97 & 8.11 & 2.34 & 4.48 \\
\hline ML-21 & 80.27 & 44.15 & 18.8 & 75.5 & 112.8 & 17.8 & 24.67 & 199.2 & 2.75 & 39.79 & 7.88 & 2.34 & 6.37 \\
\hline ML-22 & 84.33 & 38.66 & 16.5 & 74.8 & 113.8 & 15.8 & 24.50 & 160.8 & 2.46 & 27.32 & 7.82 & 2.18 & 4.37 \\
\hline ML-23 & 87.60 & 42.31 & 16.7 & 73.2 & 112.2 & 16.7 & 24.67 & 166.0 & 2.41 & 29.50 & 7.61 & 2.21 & 4.72 \\
\hline ML-24 & 86.13 & 36.46 & 17.7 & 74.8 & 113.8 & 17.0 & 24.17 & 158.8 & 2.42 & 28.54 & 7.58 & 2.24 & 4.57 \\
\hline ML-25 & 84.27 & 40.54 & 18.0 & 76.0 & 115.0 & 18.7 & 24.17 & 163.5 & 2.63 & 38.48 & 7.57 & 2.25 & 6.16 \\
\hline ML-26 & 89.87 & 34.95 & 19.3 & 76.5 & 115.5 & 19.5 & 24.50 & 158.5 & 2.51 & 32.07 & 8.01 & 2.34 & 5.13 \\
\hline ML-27 & 84.13 & 37.62 & 18.8 & 74.0 & 113.0 & 18.3 & 24.50 & 153.0 & 2.48 & 36.83 & 7.73 & 2.26 & 5.89 \\
\hline ML-28 & 91.80 & 41.72 & 17.2 & 75.0 & 114.0 & 16.8 & 24.67 & 152.8 & 2.50 & 29.50 & 7.99 & 2.40 & 4.72 \\
\hline ML-29 & 83.33 & 39.37 & 18.3 & 72.2 & 111.2 & 15.8 & 24.67 & 155.2 & 2.59 & 31.73 & 7.95 & 2.35 & 5.08 \\
\hline ML-30 & 83.47 & 39.50 & 17.3 & 75.3 & 114.3 & 15.3 & 24.67 & 155.8 & 2.42 & 27.34 & 8.31 & 2.36 & 4.38 \\
\hline ML-31 & 83.67 & 36.13 & 16.8 & 72.3 & 111.3 & 16.3 & 24.50 & 167.8 & 2.43 & 29.23 & 8.00 & 2.31 & 4.68 \\
\hline MR 219 & 85.27 & 40.39 & 15.7 & 76.0 & 115.0 & 15.7 & 23.33 & 143.8 & 2.38 & 30.52 & 7.85 & 2.34 & 4.88 \\
\hline MR 220 & 85.87 & 41.08 & 16.8 & 74.3 & 113.3 & 14.7 & 24.67 & 142.5 & 2.71 & 28.74 & 7.87 & 2.33 & 4.60 \\
\hline MR 253 & 82.60 & 29.29 & 16.8 & 67.2 & 106.2 & 15.5 & 24.67 & 129.3 & 2.66 & 26.62 & 7.85 & 2.22 & 4.26 \\
\hline MR 264 & 81.40 & 36.67 & 15.8 & 71.7 & 110.7 & 15.7 & 24.50 & 111.3 & 2.46 & 34.84 & 7.91 & 2.32 & 5.58 \\
\hline Binadhan-4 & 128.50 & 52.54 & 19.8 & 64.8 & 95.8 & 17.2 & 26.67 & 148.7 & 2.63 & 34.27 & 7.52 & 2.06 & 5.48 \\
\hline Binadhan-5 & 99.47 & 43.90 & 19.8 & 59.2 & 98.2 & 18.3 & 22.83 & 102.8 & 2.40 & 31.18 & 6.65 & 1.98 & 4.99 \\
\hline Binadhan-6 & 110.50 & 42.76 & 14.2 & 62.5 & 101.5 & 15.5 & 25.50 & 139.2 & 2.27 & 34.83 & 5.87 & 1.73 & 5.57 \\
\hline Binadhan-7 & 73.20 & 27.63 & 16.0 & 55.5 & 94.5 & 15.5 & 23.67 & 122.7 & 2.24 & 20.62 & 6.93 & 1.98 & 3.30 \\
\hline Binadhan-10 & 81.80 & 34.08 & 21.0 & 61.2 & 100.2 & 19.7 & 23.17 & 91.2 & 2.54 & 30.16 & 6.39 & 1.84 & 4.83 \\
\hline Binadhan-8 & 96.93 & 54.31 & 18.3 & 55.3 & 94.3 & 19.5 & 23.67 & 99.7 & 2.81 & 28.38 & 5.68 & 1.71 & 4.54 \\
\hline IRATOM-38 & 71.47 & 31.41 & 22.0 & 53.2 & 85.8 & 18.8 & 22.67 & 127.5 & 2.48 & 21.33 & 6.45 & 1.83 & 3.41 \\
\hline Binasail & 147.70 & 72.89 & 26.2 & 64.2 & 124.7 & 21.7 & 31.33 & 220.3 & 1.73 & 24.84 & 5.12 & 1.67 & 3.98 \\
\hline VN-124 & 78.40 & 22.98 & 22.5 & 57.7 & 96.7 & 21.3 & 22.33 & 111.2 & 2.39 & 21.38 & 7.65 & 2.26 & 3.42 \\
\hline $\mathrm{VN}-121$ & 79.00 & 22.32 & 19.3 & 56.2 & 95.2 & 19.5 & 23.50 & 135.5 & 2.27 & 29.29 & 7.36 & 2.14 & 4.69 \\
\hline $\operatorname{LSD}(P \leq 0.05)$ & 6.85 & 3.92 & 2.1 & 3.15 & 3.6 & 2.8 & 1.40 & 25.7 & 0.14 & 9.18 & 0.44 & 0.28 & 1.47 \\
\hline
\end{tabular}


of panicles (21) was found in Binasail, which was statistically similar to Binadhan-5, Binadhan-8, IRATOM-38, VN121, VNI24, and Binadhan-10. The lowest number of panicles (13) was observed in ML12 (12.83) which was statistically similar to ML7. However, genotypes ML-29, ML-19, ML-22, ML-2, MR 219, MR 264, MR 253, Binadhan-6, Binadhan-7, ML-5, ML-30, ML-11, and ML-14 had similar number of panicles. The differences in the number of panicles produced among the genotypes were significantly significant $(P<0.01)$. The panicle length ranged from 31.33 to $22.33 \mathrm{~cm}$ and the highest $(31.33 \mathrm{~cm})$ was observed in Binasail followed by Binadhan$4(26.67 \mathrm{~cm})$ while the shortest panicle length $(22.33 \mathrm{~cm})$ was recorded in VN124 which was statistically similar to Binadhan-5, ML-14, ML-2, and IRATOM-38. The highest number of filled grains (181) was from ML-21 while the lowest (65) was from Binadhan-7. A significant difference was observed for grain per panicle among all varieties, with values that ranged from 220 to 91 . The highest number of grain per panicle (220) was observed in Binasail, which was statistically similar to ML-10 and ML- 4 but differed from the rest of the genotypes. The lowest number of grains per panicle (91) was observed in Binadhan-10. The highest amount of total grain weight per hill belonged to ML-9, whereas ML12 had the lowest amount of total grain weight per hill. The 100 grain weight varied significantly among the genotypes, with the weight ranging from 2.85 to $1.73 \mathrm{~g}$. ML-3 had the highest value of 100 grain weight $(2.85 \mathrm{~g})$, which was not significantly different from ML-10, ML-21, ML-9, MR 220, and Binadhan-8. The lowest 100 grain weight $(1.73 \mathrm{~g})$ was recorded in Binasail (Table 3). The seed length also varied significantly among the genotypes, ranging from 8.31 to $5.11 \mathrm{~mm}$. ML-30 had the longest $(8.31 \mathrm{~mm})$ seeds, whereas Binasail had the shortest $(5.11 \mathrm{~mm})$ seeds. The grain shape varied significantly among the genotypes, with values ranging from 2.4 to $1.66 \mathrm{~mm}$. The highest seed length to width ratio $(2.4 \mathrm{~mm})$ was found in ML-14, whereas the lowest value $(1.66 \mathrm{~mm})$ was observed in Binasail. The highest yield/ha (7.12 ton/ha) was found in genotype ML-9, followed by ML4 (6.72 ton/ha), whereas the lowest value ( 2.87 ton/ha) was observed in ML-12 (Table 3).

3.3. Heritability, Selection Gain, and Coefficient of Variation. In this study, broad sense heritability was high for all the traits except total grain weight (28\%), yield per hectare (44\%), and seed length to width ratio (45\%) (Table 4). The highest heritability value (98\%) was found in 100 grain weight, whereas days to flowering, days to maturity, and plant height had $91 \%$, 91\%, and $89 \%$ values, respectively. In addition, high level of variability was observed in genotypic coefficient of variation (GCV) and phenotypic coefficient of variation (PCV). The high values of GCV were recorded from flag leaf length to width ratio (28.31\%) and yield per hectare $(22.53 \%)$ whereas the low values were found in panicle length $(7.2 \%)$, 100 grain weight $(9.49 \%)$, and days to maturity $(9.66 \%)$. The highest PCV value was found in yield per hectare $(34.14 \%)$ whereas the lowest value was recorded from panicle length (8.78\%). Furthermore, the genetic advance (GA) for 13 traits had its peak with the flag leaf length to width ratio $(55.77 \%)$ followed by the plant height (38.57\%), whereas the lowest value were recorded from the panicle length (12.15\%) and from seed length to width ratio (14.18\%) (Table 4).

3.4. Relationship between Traits. Correlation coefficients among morphological traits and yield and its components showed that all the traits had a positive correlation with yield, except for the number of tillers (Table 5). The total grain weight significantly correlated with the flag leaf length to width ratio, days to flowering, days to maturity, leaf area, and panicle length (Table 5).

3.5. Cluster Analysis of Morphological Traits. The standardized morphological data were employed to calculate the Euclidean distances among the 45 genotypes and a UPGMA dendrogram was constructed using these values as indicated in Table 6 and Figure 1. In this dendrogram, the 45 rice genotypes were grouped into 5 primary clusters based on 13 morphological traits. Among the five clusters, cluster I had the largest number of genotypes (35), cluster II had 2 genotypes, and cluster III had 3 genotypes. Cluster IV had 4 genotypes whereas cluster $\mathrm{V}$ contained only a genotype.

\section{Discussion}

The traits assessed in 45 rice accessions showed significant differences among themselves. This pointed at the existence of variation in the population. The differences exhibited by the genotypes could be because they originated from different areas. In this direction, several reports have been published on phenotypic variation among rice genotypes [1720]. Similarly, Pandey et al. [21] reported highly significant differences among 40 rice accessions with the use of 12 quantitative characters. In the same vein, [22] discovered 95\% differences among five rice populations by using 20 morphological characters. The high-yielding genotypes were short. This feature was as a result of short internode. This could equally be attributed to very effective assimilate partitioning at the expense of vegetative growth. So, instead of having tall plants, high yield came as a compensation for the vegetative deficiency. This trait is also advantageous in protection against lodging. Though plant height is mostly governed by the genetic makeup of the genotype, it is highly influenced by environmental factors. As indirectly pointed out earlier, rice yield is indirectly related to its height. This is due to sink competition for the limited photosynthates produced by limited sources. So what will be used for yield increase will be unnecessarily used for somatic cell enlargement that results in luxuriant vegetative growth and enhanced height. Therefore, tall varieties normally have lower yield than the short ones. Another serious disadvantage of tallness rice is lodging which significantly lowers the final yield and makes the plants prone to some other natural attacks. In this experiment, all the high-yielding varieties were found to be of intermediate height. This implies that moderate plant height is desirable when breeding for high-yielding varieties. Flag leaf plays a significant role in enhancing rice yield because it remains the only source of assimilate production for the filling spikelets 


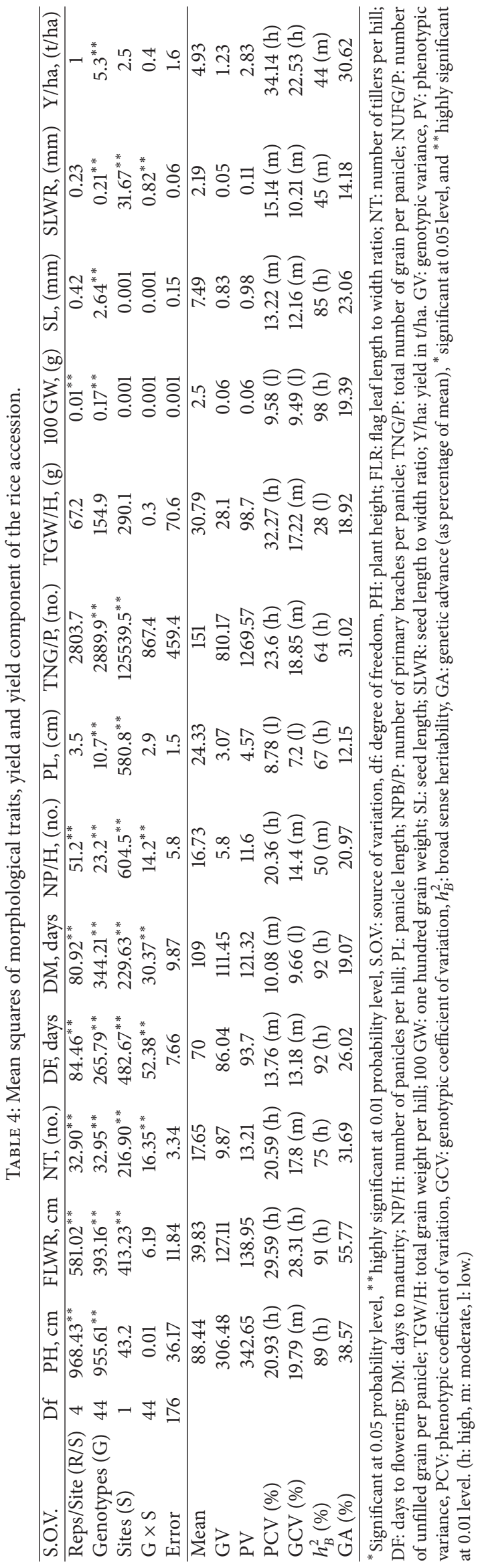




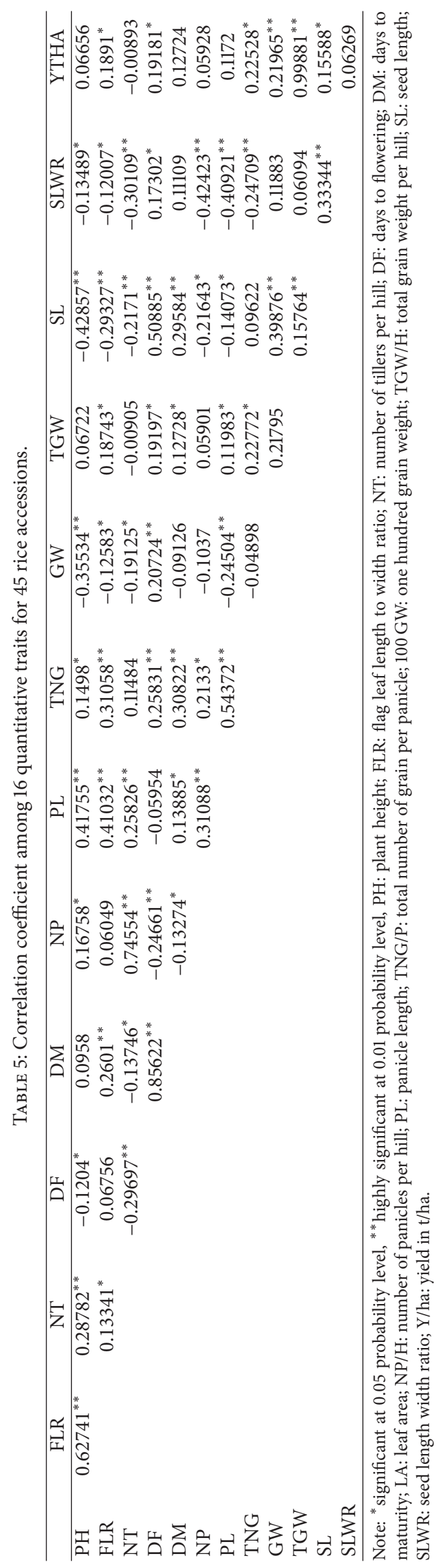


TABLE 6: Grouping of 45 genotypes according to cluster analysis.

\begin{tabular}{lcc}
\hline Cluster number & Number of genotypes & Genotypes \\
\hline I & 35 & GN1, GN2, GN3, GN4, GN5, GN6, GN7, GN8, GN9, GN10, GN11, GN12, GN13, \\
& 2 & GN14, GN15, GN16, GN17, GN18, GN19, GN20, GN21, GN22, GN23, GN24, \\
II & GN25, GN26, GN27, GN28, GN29, GN30, GN31, GN32, GN33, GN34, GN35 \\
III & 3 & G36, G38 \\
IV & 4 & G37, G40, G41 \\
V & 1 & G39, G42, G44, G45 \\
\hline
\end{tabular}

Note: GN1 = ML-1, GN2 = ML-2, GN3 = ML-3, GN4 = ML-4, GN5 = ML-5, GN6 = ML-6, GN7 = ML-7, GN8 = ML-8, GN9 = ML-9, GN10 = ML-10, GN11 = ML-11, GN12 = ML-12, GN13 = ML-13, GN14 = ML-14, GN15 = ML-15, GN16 = ML-16, GN17 = ML-17, GN18 = ML-18, GN19= ML-19, GN20 = ML-20, GN21 $=$ ML-21, GN22 = ML-22, GN23 = ML-23, GN24 = ML-24, GN25 = ML-25, GN26 = ML-26, GN27 = ML-27, GN28 = ML-28, GN29= ML-29, GN30 = ML-30, GN31 = ML-31, GN32 = MR 219, GN33 = MR 220, GN34 = MR 253, GN35 = MR 264, GN36 = Binadhan-4, GN37 = Binadhan-5, GN38 = Binadhan-6, GN39 = Binadhan-7, GN40 = Binadhan-10, GN41 = Binadhan-8, GN42 = IRATOM-38, GN43 = Binasail, GN44 = VN-124, and GN45= VN-121.

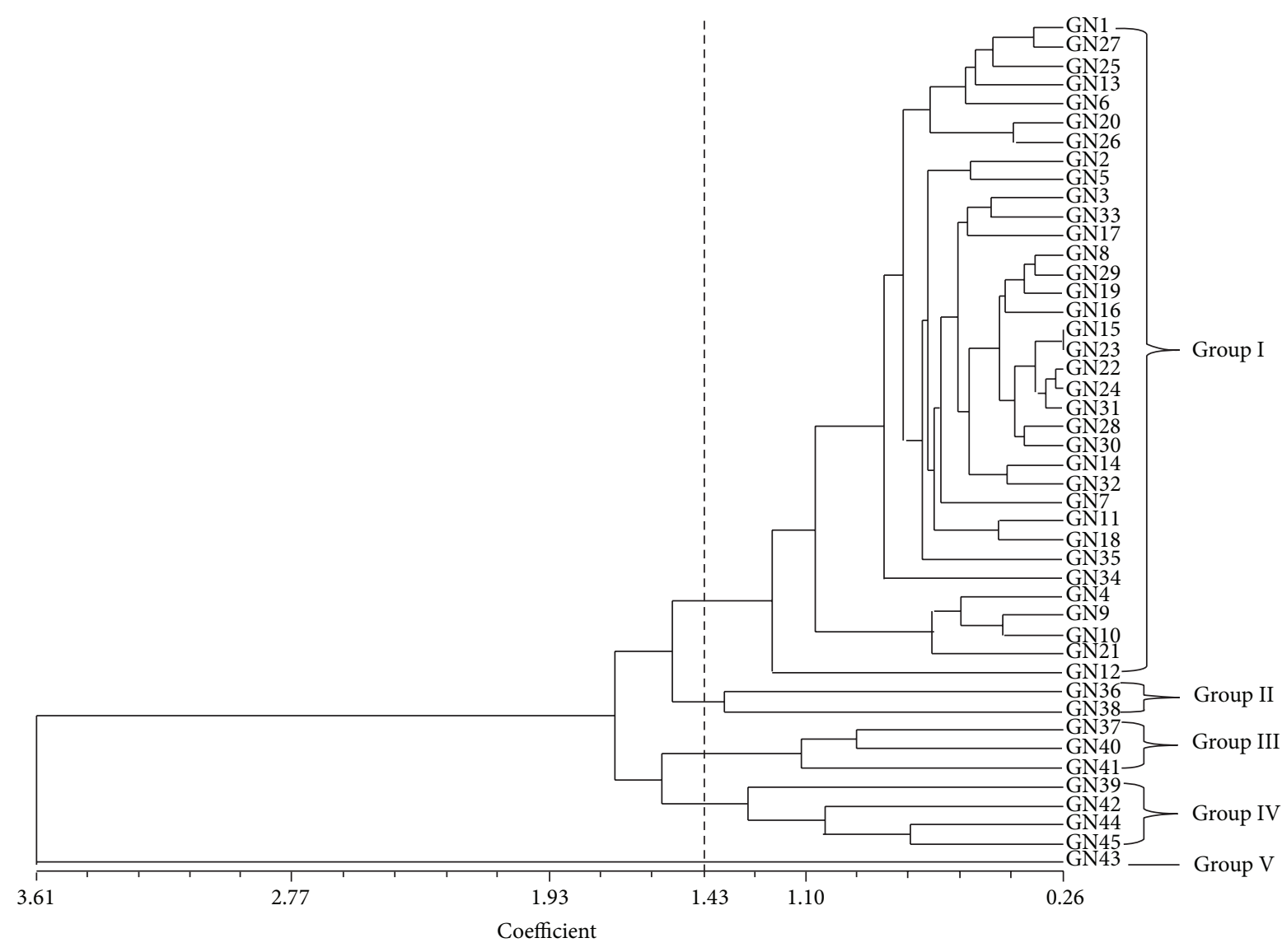

FIGURE 1: Clustering pattern of the morphological trait at dissimilarity coefficient of 1.43.

during grain-filling stage $[23,24]$. The larger the leaf area, the more the solar interception and photosynthate production provided that all other factors of production are not limiting. Therefore, flag leaf area was found to be directly related to the yield components: number of panicles, panicle length, number of grains per panicle, 100 grain weight, total grain weight per hill, and yield per hectare. Furthermore, the flag leaf has been found to be metabolically active to support higher grain yield. Corroborating our finding in this work, Ashrafuzzaman et al. [25] have made it clear that yield components positively correlate with flag leaf area. Number of tillers plays a significant role in determining yield of the rice grain since it is directly related to panicle number that will be produced per unit ground area. Fewer tillers result in fewer panicles; excess tillers cause high tiller abortions, small panicles, poor grain filling, and reduction in grain yield [21]. It has been observed that leaf area index and plant nitrogen status are the two major factors that affect tiller production in rice crops [21]. When there is adequate nutrient supply, mitotic cell division will be enhanced and 
growth of tillers and plant general vegetative life will receive a boost. In this work, the tiller production was between moderate and low levels. So the case of tiller abortion was not a problem during production period. The number of panicles per hill was between moderate (21) and low (13). This correlates with the number of tillers produced. So the number of effective tillers rests on the number of tillers produced and this is directly proportional to the panicles produced per unit area and finally depends on variety [26]. The panicle number is an important character which directly influences the yield. Therefore, yield could be increased when agronomic manipulation is used to increase the number of panicles produced per unit area. Among yield contributing characters is panicle length. This is proportional to the number of potential spikelets to be filled during grain-filling stage.

Rice plants will naturally have the superior spikelets filled before the inferior ones. The superior spikelets are located on the primary branches located at the apex of the rice plant. So they fill faster and produce heavier and larger grain weight. On the other hand, inferior spikelets are usually located on secondary branches and are usually slow in filling. They also produce poorly filled spikelets or sterile ones [27]. Slow grain-filling rate and low grain weight of inferior spikelets have often been attributed to limitation in carbohydrate supply [27]. According to [28], the fundamental factors responsible for variations in grain filling between the superior and inferior spikelets remain unknown. As it could be seen from this study, some varieties flower earlier than the others. Those that flowered earlier matured early while those that flowered late had a delay in their maturity. Early flowering indicates short life cycle and is considered a positive character for rice improvement. Early maturing varieties are advantageous in areas with short rainfall duration because they grow faster during the vegetative phase and are thus more competitive with weeds. They reduce weed control costs and utilize less water [29]. It is a known fact that drought frequently impedes production of rain-fed lowland rice [30]. So when drought occurs towards the reproductive stage of rice production, pollination, and fertilization as well as grain filling are severely affected and panicle blanking may result. In the situation, early maturing variety will give remedial measures in lieu of establishment of irrigation facilities and development of drought-tolerant varieties [30].

The number of filled grains among the varieties ranged from high (181) to low (65). Increase in number of filled grains could be attributed to efficient translocation of carbohydrates from the sources to the spikelets (sinks) which consequently leads to increase in grain yield [31]. The varietal yield in this work was between high and low. Yield differences among different rice varieties have been reported anytime a comparison is made between different varieties of rice in both field and glasshouse trials [32]. The differences are genetically based, though environment has a great contribution in the manifestation of the inherent potential. In this work, the genotypes with higher number of effective tillers as well as higher number of grains per panicle also had higher yield. This is in line with the observation of [33]. The weight of 100 or 1000 grain weight contributes significantly to the final yield per unit area. It represents the weight of individual seeds which could not be directly measured because of the size of individual seeds. The result of the present study showed that 100 grain weight varied significantly among the tested varieties. This could also be due to their differences in origin and genetic makeup. Similar reports have been published by a BRRI scientist [34] as well as Ashrafuzzaman et al. [25]. Panicle length determines how many spikelets will be found in a panicle and therefore filled spikelets and consequently final grain yield. The longer the panicle, the more the spikelets and the filled grains, if other environmental conditions are not limiting. As found here, panicle length correlated positively with the final yield. Credence to this research finding has been laid by [35] who also found a significant positive association between panicle length and grain yield per hill.

Heritability is the proportion of phenotypic traits (physical appearance) or total variance that is inherited from the parents. Higher genotypic coefficient of variation together with high heritability as well as high genetic advance gives better clues than individual parameters. Thus, the traits with high genotypic coefficient of variation, heritability, and genetic advance are selected. In this study, flag leaf length to width ratio, plant height, and the total number of grains per panicle had higher values for genotypic coefficient of variation, heritability, and genetic advance. Therefore, selection with a view to develop one trait which will positively influence other traits is of paramount importance.

Having positive correlation coefficients between the vegetative traits and the yield parameters in this work was an indication that the quantitative traits measured were appropriate for yield prediction and selection for breeding programmes to obtain better vigour or heterosis. The positive correlation between the final yield and plant height and total number of grain per panicle and days to maturity indicates that better exploration of these three traits could be used to develop desired genotypes.

The contribution of individual panicle grain yield sums up to produce the final yield. Therefore, high panicle grain yield could be successfully used as an important selection index for grain yield [36]. Furthermore, when the panicle yield is correlated with the yield per unit area, positive correlation coefficient will result [37]. In the present study, yield per panicle had the best relationship with yield production. Hence, more attention is given to this trait for final yield determination in all the assessed genotypes.

The UPGMA dendrogram broadly clustered the rice genotypes into five major groups at 1.43 dissimilarity coefficients. This implies a high level of morphological diversity in the rice genotypes. This study revealed effectiveness of quantitative or morphological traits in grouping rice genotypes. It has been established that genetic divergence analysis among rice genotypes on the basis of morphological traits can be used to classify and differentiate different genotypes in a population [38]. This genetic divergence analysis also plays a vital role in selection of diverse genotypes for the further improvement of rice varieties through breeding [39]. We have succeeded in clustering 45 genotypes into 5 major groups using some quantitative traits for better handling of 
the diverse genotype as well as better selection for acquisition of higher heterotic vigour in the resulting offspring after crossing. Similarly, Ahmadikhah et al. [40] clustered 58 rice varieties into four groups using 18 morphological traits, while Mazid et al. [41] had his 41 rice genotypes clustered into 6 on the basis of 13 morphological traits. Therefore, to attain success in breeding for higher vigour among the genotypes, group I could be hybridized with group V or group VI in this work and as corroborated by findings of $[41,42]$.

As observed in this study, the experimented rice genotypes showed notable genetic diversity in terms of morphological traits. This shows the efficacy of ion beam radiation in inducing high performing agronomic traits in some mutant lines as compared to the control. High heritability together with high genetic advance was obtained for plant height, flag leaf length to width ratio, days to maturity, and total numbers of grains per panicle.

\section{Conclusion}

The development of rice genotypes that could lead to attainment of food security rests on exploring genetic aspects of its quantitative traits. This is because genetic variations give room for recombinants which are essential in development of new genotype. Field trials were carried out on 45 mutant rice genotypes and their genetic diversities were determined using their quantitative traits. All the genotypes showed variations for vegetative and yield traits. Also, all the traits related positively with the final yield with the exception of number of tillers. Finally, the evaluated genotypes were grouped into five major clusters based on the assessed traits with the aid of UPGMA dendrogram. So hybridization of group I with group V or group VI could be used to attain higher heterosis or vigour among the genotypes. This evaluation could be useful in developing reliable selection indices for important agronomic traits in rice. It is recommended that future research explore molecular means to further confirm the outcome of this research and establish the relationship between the two methods.

\section{Conflict of Interests}

The authors declare that there is no conflict of interests regarding the publication of this paper.

\section{Acknowledgments}

The authors would like to acknowledge the financial support of IAEA's Coordinated Research Project (CRP) for Food and Feed [CRP Code: D2.30.30]. We also appreciate Malaysia Ministry of Education for Long-Term Research Grant Scheme (LRGS) on enhancing sustainable rice production and MOSTI for Science Fund (06-03-01-SF0110).

\section{References}

[1] M. A. J. Parry, P. J. Madgwick, C. Bayon et al., "Mutation discovery for crop improvement," Journal of Experimental Botany, vol. 60, no. 10, pp. 2817-2825, 2009.
[2] L. Velasco, J. M. Fernández-Martínez, and A. De Haro, "Inheritance of reduced linolenic acid content in the Ethiopian mustard mutant N2-4961," Plant Breeding, vol. 121, no. 3, pp. 263-265, 2002.

[3] A. M. R. Ferrie, D. C. Taylor, S. L. MacKenzie, G. Rakow, J. P. Raney, and W. A. Keller, "Microspore mutagenesis of Brassica species for fatty acid modifications: a preliminary evaluation," Plant Breeding, vol. 127, no. 5, pp. 501-506, 2008.

[4] A. M. van Harten, Mutation Breeding: Theory and Practical Applications, Cambridge University Press, Cambridge, UK, 1998.

[5] A. S. Larik, S. Memon, and Z. A. Soomro, "Radiation induced polygenic mutations in Sorghum bicolor L," Journal of Agricultural Research, vol. 47, pp. 11-19, 2009.

[6] P. J. L. Lagoda, "Networking and fostering of cooperation in plant mutation genetics and breeding: role of the joint FAO/IAEA programme FAO/IEAE," in Proceedings of the International Symposium on Induced Mutations in Plants, pp. 2-3, Vienna, Austria, August 2008.

[7] R. M. Wani and S. Khan, "Estimates of genetic variability in mutated populations and the scope of selection for yield attributes in Vigna radiata (L) Wilczek," Egyptian Journal of Biology, vol. 8, pp. 1-6, 2006.

[8] B. S. Ahloowalia and M. Maluszynski, "Induced mutations-a new paradigm in plant breeding," Euphytica, vol. 118, no. 2, pp. 167-173, 2001.

[9] Z. U. Bashar, A. Wayayok, and A. M. S. Mohd, "Determination of some physical properties of common Malaysian rice MR219 seeds," Australian Journal of Crop Science, vol. 8, no. 3, pp. 332337, 2014.

[10] R. K. Singh and B. D. Choudhary, Biometrical Methods in Quantitative Genetic Analysis, Kalyani Publishers, New Delhi, India, 1985.

[11] S. S. Sivasubramanian and P. Madhava Menon, "Genotypic and phenotypic variability in rice," Madras Agricultural Journal, vol. 60, pp. 1093-1096, 1973.

[12] D. S. Falconer, Introduction to Quantitative Genetics, Longman, New York, NY, USA, 3rd edition, 1989.

[13] H. F. Robinson, R. E. Comstock, and P. H. Harvey, "Genotypic and phenotypic correlation in corn and their implications in selection," Agronomy Journal, vol. 43, pp. 282-287, 1949.

[14] K. Assefa, S. Ketema, H. Tefera et al., "Diversity among germplasm lines of the Ethiopian cereal tef [Eragrostis tef (Zucc.) Trotter]," Euphytica, vol. 106, no. 1, pp. 87-97, 1999.

[15] H. W. Johnson, H. F. Robinson, and R. E. Comstock, "Estimation of genetic and environmental variability in soybeans," Agronomy Journal, vol. 47, pp. 314-318, 1955.

[16] A. Melchinger, M. Messmer, M. Lee, W. Woodman, and K. Lamkey, "Diversity and relationships among US maize inbreeds reveal by restriction fragment length polymorphisms," Crop Science, vol. 31, no. 3, pp. 621-678, 1991.

[17] T. Shehzad, A. Allah, A. El Naby, A. Allah, M. Ammar, and A. Abdelkhalik, "Agronomic and molecular evaluation of induced mutant rice (Oryza sativa L.) lines in Egypt," Pakistan Journal of Botany, vol. 43, no. 2, pp. 1183-1194, 2011.

[18] A. Babaei, G.-A. Nematzadeh, and H. Hashemi, "An evaluation of genetic differentiation in rice mutants using semi-random markers and morphological characteristics," Australian Journal of Crop Science, vol. 5, no. 13, pp. 1715-1722, 2011.

[19] K. Elayaraja, M. Prakash, K. Saravanan, S. B. Kumar, and J. Ganesan, "Studies on variability, heritability and genetic 
advance for certain quantitative characters in mutant population of rice (Oryza sativa L.)," Crop Research Hisar, vol. 1, pp. 134-137, 2005.

[20] S. S. Meheter, A. P. Patil, R. C. Mahajan, and B. R. Shinde, "Variability, heritability, character association and genetic divergence studies in M2 generation of gamma irradiation upland paddy," Crop Research Hisar, vol. 12, no. 2, pp. 155-161, 1996.

[21] P. Pandey, P. John Anurag, D. K. Tiwari, S. K. Yadav, and B. Kumar, "Genetic variability, diversity and association of quantitative traits with grain yield in rice (Oryza sativa L.)," Journal of Bio-Science, vol. 17, no. 1, pp. 77-82, 2009.

[22] S. Padmaja Rao, "Influence of source and sink on the production of high density grain and yield in rice," Indian Journal of Plant Physiology, vol. 34, pp. 339-348, 1991.

[23] A. Raj and M. P. Tripathi, "Varietal variations in flag leaf area and yield in deep water rice," Indian Journal of Plant Physiology, vol. 5, no. 3, pp. 293-295, 2000.

[24] J.-L. Wang, Y.-B. Gao, N.-X. Zhao et al., "Morphological and RAPD analysis of the dominant species Stipa krylovii Roshev. in Inner Mongolia steppe," Botanical Studies, vol. 47, no. 1, pp. 23-35, 2006.

[25] M. Ashrafuzzaman, M. R. Islam, M. R. Ismail, S. M. Shahidullah, and M. M. Hanafi, "Evaluation of six aromatic rice varieties for yield and yield contributing characters," International Journal of Agriculture and Biology, vol. 11, no. 5, pp. 616-620, 2009.

[26] M. B. Hossain, M. O. Islam, and M. Hasanuzzaman, "Influence of different nitrogen levels on the performance of four aromatic rice varieties," International Journal of Agriculture and Biology, vol. 10, no. 6, pp. 693-696, 2008.

[27] J. Yang and J. Zhang, "Grain filling of cereals under soil drying," New Phytologist, vol. 169, no. 2, pp. 223-236, 2006.

[28] A. Mostajeran and V. Rahimi-Eichi, "Effects of drought stress on growth and yield of rice (Oryza sativa L.) cultivars and accumulation of proline and soluble sugars in sheath and blades of their different ages leaves," American-Eurasian Journal of Agricultural \& Environmental Science, vol. 5, pp. 264-272, 2009.

[29] G. S. Khush, "Modern varieties-their real contribution to food supply and equity," GeoJournal, vol. 35, no. 3, pp. 275-284, 1995.

[30] S. M. Haefele and B. A. M. Bouman, "Drought-prone rainfed lowland rice in Asia: limitations and management options in," in Drought Frontiers in Rice: Crop Improvement for Increased Rainfed Production, J. Serraj, J. Bennett, and B. Hardy, Eds., pp. 211-232, World Scientific Publishing, Singapore, 2009.

[31] Z.-Z. Xu and G.-S. Zhou, "Photosynthetic recovery of a perennial grass Leymus chinensis after different periods of soil drought," Plant Production Science, vol. 10, no. 3, pp. 277-285, 2007.

[32] J. K. Biswas, M. A. Hossain, B. C. Sarker, M. Hassan, and M. Z. Haque, "Yield performance of several rice varieties seeded directly as late Aman crops," Bangladesh Journal of Life Sciences, vol. 10, pp. 47-52, 1998.

[33] R. K. Dutta, M. A. Basetmai, and S. Khanam, "Plant architecture and growth characteristics of fine grain and aromatic rice and their relation with grain yield," IRC Newsletter, vol. 51, pp. 105111, 2001.

[34] BRRI, Annual Report 1996-1997, Bangladesh Rice Research Institute, Gazipur, Bangladesh, 1997.

[35] R. Chakraborty and S. Chakraborty, "Genetic variability and correlation of some morphometric traits with grain yield in bold grained rice (Oryza sativa L.) gene pool of Barak valley," American-Eurasian Journal of Sustainable Agriculture, vol. 4, no. 1, pp. 26-29, 2010.
[36] T. Meenakshi, A. A. D. Ratinam, and S. Backiyarani, "Correlation and path analysis of yield and some physiological characters in rain fed rice," Oryza, vol. 6, pp. 154-156, 1999.

[37] M. A. Mustafa and M. A. Y. Elsheikh, "Variability, correlation and path co-efficient analysis for yield and its components in rice," African Crop Science Journal, vol. 15, no. 4, pp. 183-189, 2007.

[38] J. Franco, J. Crossa, J. M. Ribaut, J. Bertran, M. L. Warburton, and M. Khairallah, "A method for combining molecular markers and phenotypic attributes for classifying plant genotypes," Theoretical and Applied Genetics, vol. 103, no. 6-7, pp. 944-952, 2001.

[39] S. M. Shahidullah, M. M. Hanafi, M. Ashrafuzzaman, M. Razi Ismail, M. A. Salam, and A. Khair, "Biomass accumulation and energy conversion efficiency in aromatic rice genotypes," Comptes Rendus Biologies, vol. 333, no. 1, pp. 61-67, 2010.

[40] A. Ahmadikhah, S. Nasrollanejad, and O. Alishah, "Quantitative studies for investigating variation and its effect on heterosis of rice," International Journal of Plant Production, vol. 2, pp. 297308, 2008.

[41] M. S. Mazid, M. Y. Rafii, M. M. Hanafi, H. A. Rahim, M. Shabanimofrad, and M. A. Latif, "Agro-morphological characterization and assessment of variability, heritability, genetic advance and divergence in bacterial blight resistant rice genotypes," South African Journal of Botany, vol. 86, pp. 15-22, 2013.

[42] M. A. Latif, M. M. Rahman, M. S. Kabir, M. A. Ali, M. T. Islam, and M. Y. Rafii, "Genetic diversity analyzed by quantitative traits among rice (Oryza sativa L.) genotypes resistant to blast disease," African Journal of Microbiology Research, vol. 5, no. 25, pp. 4383-4391, 2011. 

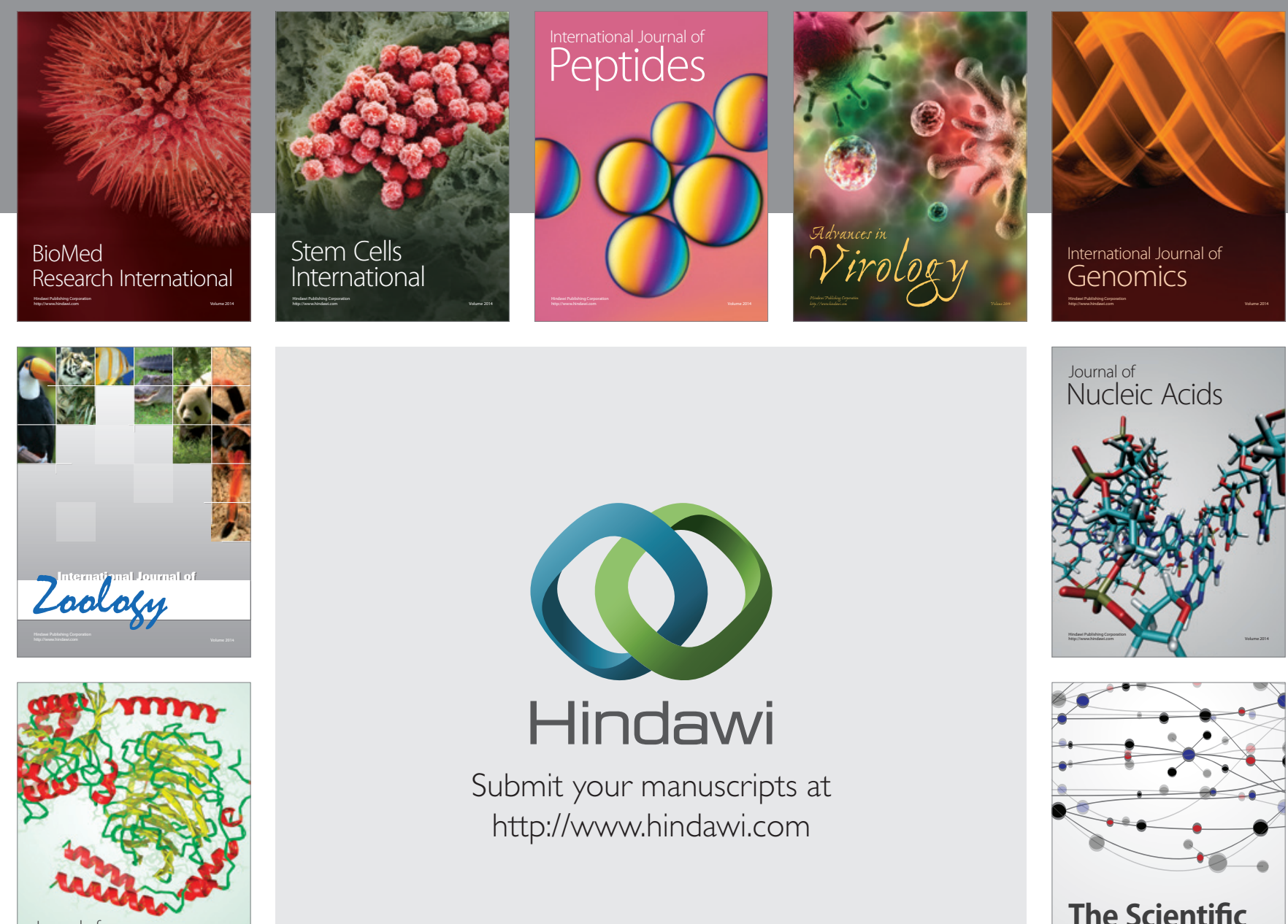

Submit your manuscripts at

http://www.hindawi.com

Journal of
Signal Transduction
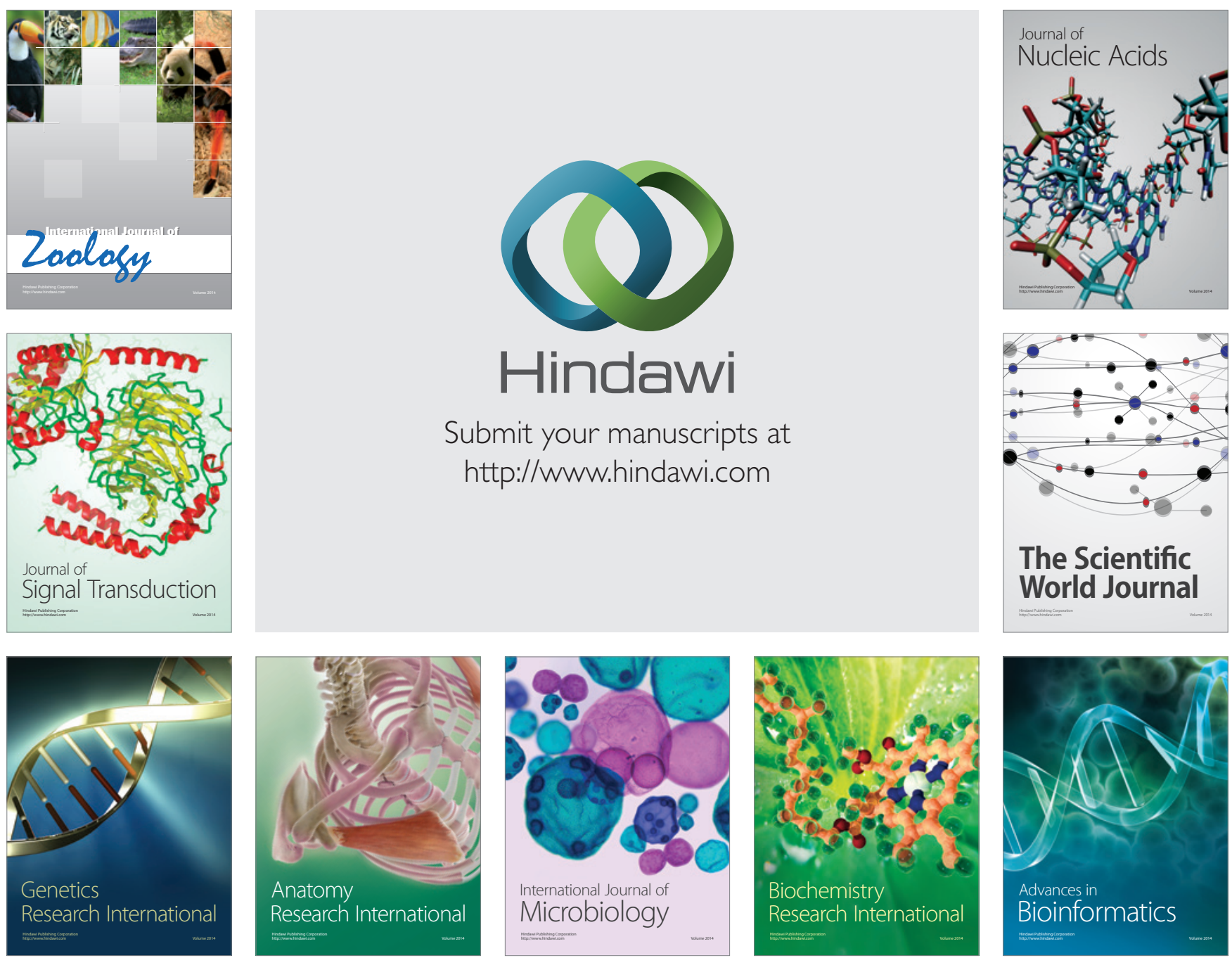

The Scientific World Journal
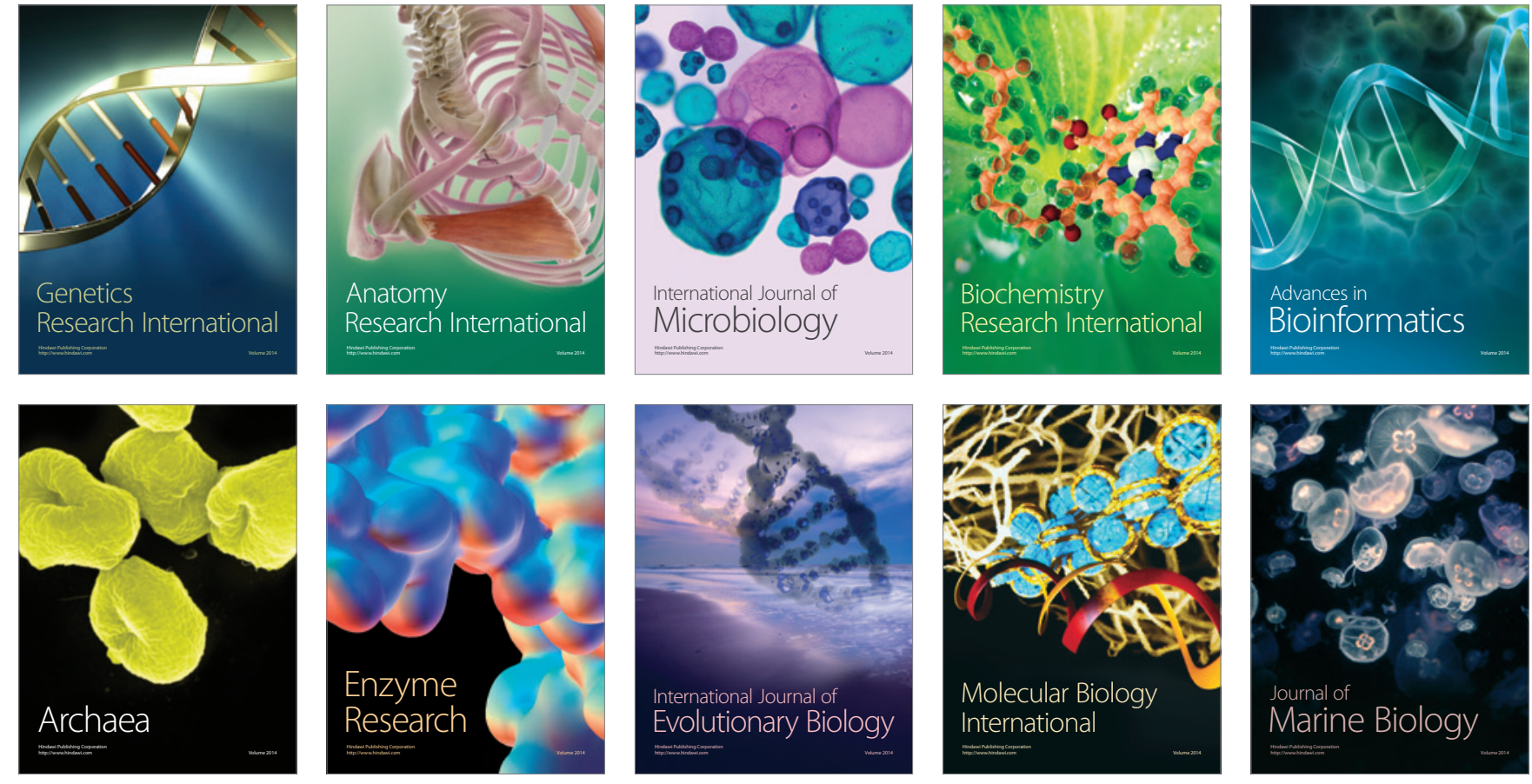